11

\title{
Полевая эмиссия многоострийных кремниевых структур с защитными покрытиями
}

\author{
(C Г.Г. Соминский, ${ }^{1}$ Е.П. Тарадаев, ${ }^{1}$ Т.А. Тумарева, ${ }^{1}$ М.Е. Гиваргизов, ${ }^{2}$ А.Н. Степанова ${ }^{2}$ \\ ${ }^{1}$ Санкт-Петербургский политехнический университет Петра Великого, \\ 195251 Санкт-Петербург, Россия \\ ${ }^{2}$ Институт кристаллографии РАН, \\ 119333 Москва, Россия \\ e-mail: sominski@rphf.spbstu.ru
}

(Поступило в Редакцию 26 фревраля 2016 г.)

Исследована работа многоострийных кремниевых эмиттеров большой площади $\left(\sim 0.1-0.3 \mathrm{~cm}^{2}\right)$ с двухслойными металл-фуллереновыми покрытиями. Продемонстрирована возможность создания источников полевой эмиссии, обеспечивающих токи в несколько десятков миллиампер, достаточные для работы некоторых типов СВЧ-устройств коротковолнового миллиметрового и субмиллиметрового диапазона, а также портативных источников рентгеновского излучения. Получены свидетельства возможности стабильной эксплуатации многоострийных кремниевых полевых эмиттеров с двухслойными металл-фулереновыми покрытиями в высоковольтных электронных приборах при отборе больших токов в условиях технического вакуума.

\section{Введение}

Холодные полевые эмиттеры привлекают к себе внимание прежде всего тем, что не требуют накала и безынерционны. Традиционно и успешно они используются при создании устройств аналитического приборостроения (например, всевозможных электронных микроскопов и сенсоров). В таких приложениях важно еще одно их свойство - способность обеспечивать высокие плотности тока эмиссии, которые достигают значений более $10^{4} \mathrm{~A} / \mathrm{cm}^{2}$ с одиночного эмиссионного центра малого (нанометрового) размера. Однако в указанных приложениях не требуется получать больших токов. Как правило, необходимы токи с эмиттера не более $10^{-7}-10^{-6} \mathrm{~A}$.

В последние годы делаются попытки освоить не совсем обычную область применения полевых эмиттеров, использовать их при создании некоторых типов высоковольтных, но миниатюрных электронных приборов, таких, например, как СВЧ усилители и генераторы миллиметрового и субмиллиметрового диапазонов (см., например, $[1,2])$, а также портативные источники рентгеновского излучения (см., например, $[3,4])$. Здесь холодные полевые эмиттеры более привлекательны, чем термокатоды. В указанных приложениях полевые эмиттеры должны обеспечивать одновременно не только высокие плотности тока эмиссии (обычно порядка или более $100-150 \mathrm{~mA} / \mathrm{cm}^{2}$ ), но и большие полные токи (свыше нескольких десятков миллиампер), причем в условиях технического вакуума. Токи и плотности токов такого масштаба могут обеспечить некоторые типы существующих многоострийных катодов (см., например, [5]). Однако даже при условии выполнения требований по токовым характеристикам, применению полевых эмиттеров в высоковольтных приборах в условиях технического вакуума препятствует невысокая их долговечность.
Основные причины выхода из строя полевых эмиттеров в высоковольтных электронных устройствах - pacпыление их поверхности под действием бомбардировки ионами остаточного газа, а также разрушение эмиттеров из-за перегрева эмитирующих электроны структур при отборе больших токов и/или под действием пондеромоторных сил. Ведется поиск путей обеспечения высокой долговечности полевых эмиттеров при их эксплуатации в высоковольтных электронных устройствах, работающих в техническом вакууме.

Возможны разные способы уменьшить вредное воздействие бомбардировки ионами остаточных газов. Изготовление катодов из материалов, стойких к ионной бомбардировке, принципиально может повысить их долговечность. Однако выбор материалов, пригодных для изготовления полевых эмиттеров, не очень широк и коэффициенты ионного распыления используемых материалов отличаются не сильно (см., например, [6]). Делались попытки уменьшить интенсивность ионной бомбардировки полевых эмиттеров с помощью специально сконструированных электронно-оптических систем, препятствующих попаданию ионов на катод (см., например, [7-9]). Пока возможность долговечной эксплуатации описанных в [7-9] эмиссионных структур в условиях, когда используется защита от ионной бомбардировки, не получила достаточного экспериментального подтверждения. Но даже если такое подтверждение будет получено, создание и практическое использование описанных в [7-9] эмиссионных структур сопряжено с большими трудностями в связи со сложностью технологии их изготовления.

Принципиально другой путь борьбы с разрушающим действием ионной бомбардировки был выбран в работах [10-12]. Авторы [10-12] разработали и использовали для решения этой проблемы защитные фуллереновые покрытия. Было показано, что нанесение на поверхность 
острийного полевого эмиттера покрытия из 2-4 монослоев молекул фуллерена $\mathrm{C}_{60}$ позволяет практически исключить его разрушение под действием ионной бомбардировки при эксплуатации катода в техническом вакууме $\sim 10^{-6}-10^{-4}$ Ра. Фуллереновые покрытия обладают большой работой выхода $(\sim 5.3-5.4 \mathrm{eV})$. Но обработка покрытия потоком медленных ионов калия с энергиями $\sim 40-100 \mathrm{eV}$ позволяет снизить его работу выхода на $1-1.5 \mathrm{eV}$.

Первоначально [10-12] была исследована работа острийных эмиттеров из вольфрама с активированными фуллереновыми покрытиями. Позже [13] было установлено, что активированные фуллереновые покрытия также хорошо защищают от действия ионной бомбардировки острийные эмиттеры из молибдена, из кремния, а также кремниевые эмиттеры с тонким (десятки нанометров) молибденовым покрытием. Технология создания многоострийных полевых эмиттеров с активированными фуллереновыми покрытиями достаточно воспроизводима и проста (см., например, [13]), что выгодно отличает такой метод ионной защиты от использованного в [7-9].

В настоящей работе исследована полевая эмиссия многоострийных кремниевых структур с активированными фуллереновыми покрытиями.

\section{Методика создания и исследования многоострийных кремниевых катодов с двухслойными металл-фуллереновыми покрытиями}

Выбор в качестве объекта исследования именно многоострийных кремниевых структур был продиктован тем, что технология их создания хорошо отработана в России [11] и достаточно проста. Однако применение таких систем в качестве эмиттеров, формирующих электронные потоки большой интенсивности, затруднено, причем не только потому что они неустойчивы к ионной бомбардировке, но и по той причине, что кремниевые острия имеют, как правило, малую проводимость. Кроме того, острийные кремниевые эмиттеры недостаточно прочны и разрушаются из-за перегрева и/или под действием пондеромоторных сил уже при умеренных значениях электрического поля и тока эмиссии. Как было показано нами в работах $[13,14]$, все указанные проблемы могут быть решены, если создать на поверхности эмиттера специальное двухслойное покрытие. Для повышения проводимости и прочности многоострийных эмиттеров использовались молибденовые покрытия. Для защиты от разрушающего действия ионной бомбардировки на слой металла наносилось активированное потоком ионов калия покрытие из молекул фуллерена $\mathrm{C}_{60}$.

В работе [13] были исследованы эмиттеры чрезвычайно малой площади $\sim 2 \cdot 10^{-3} \mathrm{~cm}^{2}$. Многоострийные структуры формировались на торцевой поверхности стержня из кремния диаметром $1 \mathrm{~mm}$. На участке этой поверхности диаметром $0.5 \mathrm{~mm}$ создавалась однород-

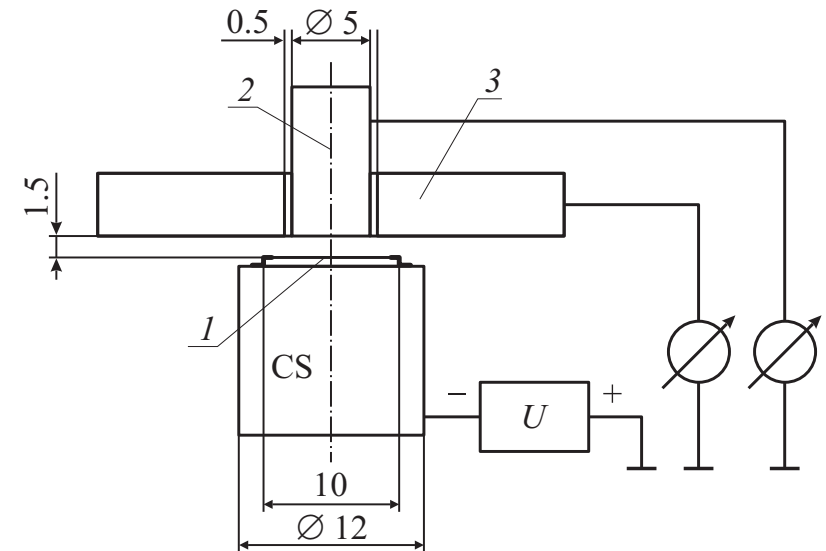

Рис. 1. Схематическое изображение сечения измерительной системы. 1 - эмиттер, закрепленный на катодной системе CS с подогревателем, 2 и 3 - электроды коллекторной системы.

ная структура из 200-300 острий. Проведенные измерения подтвердили возможность стабильной работы многоострийных эмиттеров с двухслойными защитными покрытиями в техническом вакууме. Были получены высокие средние по поверхности эмиттера плотности тока полевой эмиссии до $1 \mathrm{~A} / \mathrm{cm}^{2}$. Однако предельные полные токи с такой малой поверхности не превышали в импульсном режиме приблизительно $2 \mathrm{~mA}$.

В настоящей работе были исследованы многоострийные кремниевые эмиттеры существенно большей площади порядка $0.1-0.3 \mathrm{~cm}^{2}$. На поверхности эмиттеров, как и в работе [13], создавались двухслойные покрытия, включающие слой молибдена и активированное ионами калия фуллереновое покрытие.

Для определения эмиссионных характеристик катодов большой площади была создана измерительная система, сечение которой схематически показано на рис. 1. Здесь 1 - эмиттер, закрепленный на катодной системе CS c подогревателем, 2 и 3 - электроды коллекторной системы. Использование секционированного коллектора позволяло оценить вклад в эмиссию разных участков катода. Расстояние между катодом и коллекторной системой было равно $1.5 \mathrm{~mm}$. Все покрытия наносились на многоострийные структуры непосредственно в экспериментальном приборе. Здесь же проводилось активирование фуллереновых покрытий потоком ионов калия с энергией $40 \mathrm{eV}$. Для создания покрытий катодная система CS c эмиттером с помощью специального манипулятора перемещалась поочередно к испарителю молибдена, к источнику фуллеренов и к источнику ионов калия. Строение поверхности полевых эмиттеров контролировалось с использованием растрового электронного микроскопа типа „Supra 45 WDXC“ до установки в экспериментальный прибор и после окончания экспериментов.

Давление в измерительной системе регулировалось в пределах от $10^{-9}-10^{-10}$ Torr до $10^{-6}$ Ра напуском азота. Измерения эмиссионных характеристик выполнялись в 
техническом вакууме при давлении порядка $10^{-5} \mathrm{~Pa}$. Измерения проводились в статическом и в импульсном $(1-2 \mu \mathrm{s}, 50-100 \mathrm{~Hz})$ режимах.

\section{Результаты измерений и их обсуждение}

Чтобы свести к минимуму роль вторичных эффектов, обусловленных интенсивной электронной бомбардировкой коллектора (например, перегрева коллектора и связанного с этим газовыделения с его поверхности), измерения в статическом режиме выполнялись при токах с катода, не превышающих $1 \mathrm{~mA}$. Измерения при больших токах проводились в импульсном режиме. Типичные вольт-амперные характеристики одного из катодов с площадью эмитирующей поверхности $S \approx 0.3 \mathrm{~cm}^{2}$ приведены на рис. 2. Показаны изменения с напряжением токов $I_{2}$ и $I_{3}$ на электроды 2 и 3 коллекторной системы (рис. 1), а также суммарного тока $I_{\Sigma}$ на оба электрода. Наибольший измеренный суммарный ток эмиссии с этого катода (45 mA) был близок к предельному $I_{\max }$, при превышении которого происходило разрушение

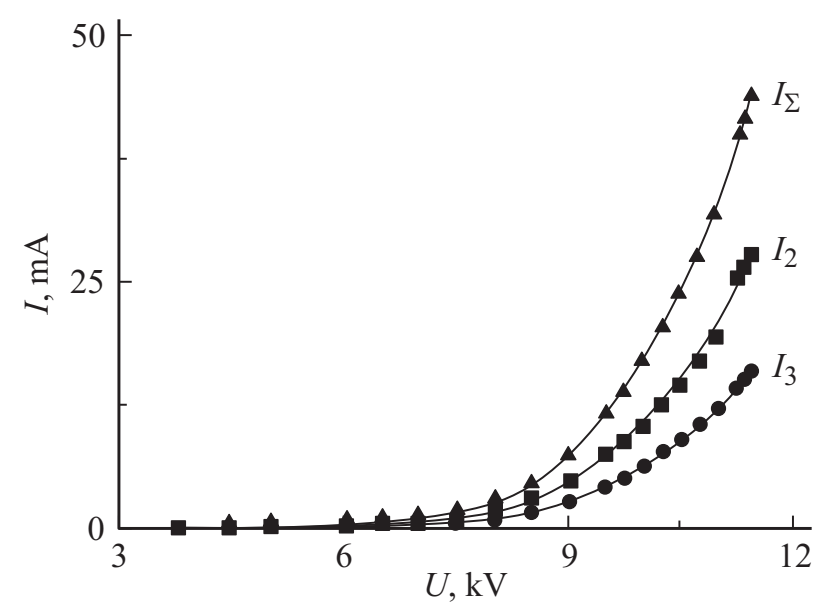

Рис. 2. Вольт-амперные характеристики катода с площадью эмитирующей поверхности $S \approx 0.3 \mathrm{~cm}^{2}$. Приведены зависимости от напряжения токов $I_{2}$ и $I_{3}$ на электроды 2 и 3 коллекторной системы, а также суммарного тока $I_{\Sigma}$ со всей катодной системы.

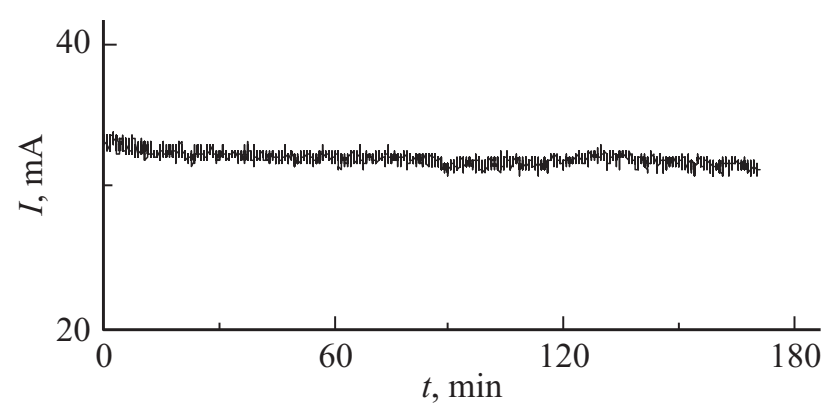

Рис. 3. Изменения во времени тока эмиссии катода с площадью эмитирующей поверхности $S \approx 0.3 \mathrm{~cm}^{2}$.

\begin{tabular}{c|c|c|c|c|c|c|c}
\hline Катод & $\begin{array}{c}D, \\
\mathrm{~nm}\end{array}$ & $\begin{array}{c}h, \\
\mu \mathrm{m}\end{array}$ & $\begin{array}{c}l, \\
\mu \mathrm{m}\end{array}$ & $\begin{array}{c}S, \\
\mathrm{~cm}^{2}\end{array}$ & $N$ & $\begin{array}{c}j, \\
\mathrm{~mA} / \mathrm{cm}^{2}\end{array}$ & $\begin{array}{c}I_{\max } \\
\mathrm{mA}\end{array}$ \\
\hline $\mathrm{C}_{1}$ & 40 & 30 & 60 & 0.1 & 3000 & 130 & 13 \\
$\mathrm{C}_{2}$ & 52 & 30 & 30 & 0.2 & 22000 & 105 & 21 \\
$\mathrm{C}_{3}$ & 40 & $15-20$ & $15-20$ & 0.3 & 95000 & 150 & 45
\end{tabular}

катода. Изменения тока во времени, характеризующие стабильность полевой эмиссии, демонстрирует рис. 3.

Проведенные измерения свидетельствуют, что предельные достижимые токи эмиссии $I_{\max }$ зависят от морфологии поверхности катодов (высоты острий $h$, диаметра их вершины $D$, расстояния между остриями $l$ ), их площади $S$ и количества $N$ острий в эмитирующей структуре. В таблице приведены данные для трех исследованных катодов $\mathrm{C}_{1}, \mathrm{C}_{2}$ и $\mathrm{C}_{3}$ : средние по поверхности катодов плотности тока эмиссии $j$ и приближенные значения предельного тока $I_{\max }$. Указаны также приближенные значения количества $N$ острий в структуре каждого катода.

Средние значения плотности тока эмиссии менялись в довольно широких пределах для разных катодов. Заметны были также изменения плотности тока эмиссии и по поверхности катода. Так, например, для катода наибольшей площади при максимальной средней плотности суммарного тока $j \approx 150 \mathrm{~mA} / \mathrm{cm}^{2}$ измеренная в том же режиме плотность тока с его центральной части приблизительно равна $130 \mathrm{~mA} / \mathrm{cm}^{2}$, а плотность тока с периферии катода имеет величину около $190 \mathrm{~mA} / \mathrm{cm}^{2}$.

Средние по поверхности плотности тока эмиссии не превышали для всех исследованных катодов большой площади даже в предельных режимах $\sim 200 \mathrm{~mA} / \mathrm{cm}^{2}$ и были существенно меньше значений, полученных в работе [13] для многоострийных кремниевых эмиттеров малой площади $\sim 2 \cdot 10^{-3} \mathrm{~cm}^{2}$. Средний ток с одиночного острия катодов большой площади не превышал $4-5 \mu \mathrm{A}$.

Падение средней плотности тока для исследованных в настоящей работе эмиттеров по сравнению с эмиттерами малой площади [13] обусловлено, как нам кажется, большей неоднородностью структуры использованных катодов большой площади. По этой причине при фиксированном анодном напряжении могут быть велики перепады тока эмиссии по структуре острий. Выход из строя катода, видимо, происходит из-за разрушения наиболее „нагруженных током“ острий. Именно это обстоятельство и не позволяет получать большие значения средней плотности тока эмиссии.

\section{Заключение}

Подытоживая результаты выполненной работы, отметим важнейшее.

- Продемонстрирована возможность создания с использованием достаточно простой технологии многоострийных кремниевых источников полевой эмиссии, 
обеспечивающих токи в несколько десятков миллиампер, достаточные для работы некоторых типов СВЧустройств коротковолнового миллиметрового и субмиллиметрового диапазонов, а также портативных источников рентгеновского излучения.

- Получены свидетельства возможности стабильной эксплуатации многоострийных кремниевых полевых эмиттеров с двухслойными металл-фуллереновыми покрытиями в высоковольтных электронных приборах при отборе больших токов в условиях технического вакуума.

\section{Список литературы}

[1] Glyavin M.Yu., Chirkov A.V., Denisov G.G. et al. // Review of scientific instruments. 2015. Vol. 86. P. 054705.

[2] Booske J.H., Dobbs R.J., Joye C.D., Kory C.L., Neil G.R., Park G.-S., Park J., Temkin R.J. // IEEE Trans. Terahertz Sci. Technol. 2011. Vol. 1. N 1. P. 54-75.

[3] Wang S., Calderon X., Peng R. at al. // Appl. Phys. Lett. 2011. Vol. 98. P. 213701.

[4] Ooki S., Ohsio S., Nishino J. at. al. // Jap. J. Appl. Phys. 2008. Vol. 47. P. 7303.

[5] Соминский Г.Г., Тумарева Т.А. // Известия вузов. Прикладная нелинейная динамика. 2015. Т. 23. Вып. 2. С. 74-93.

[6] Распыление твердых тел ионной бомбардировкой. Физическое распыление одноэлементных твердых тел / Под ред. Р. Бериша. М.: Мир, 1984. 336 с.

[7] Whaley D.R., Gannon B.M., Smith C.R. at al. // IEEE Trans. on Plasma Sci. 2000. Vol. 28. N 3. P. 727-747.

[8] Абаньшин Н.П., Горфинкель Б.И., Морев С.П., Мосияи Д.С., Якунин А.Н. // Письма в ЖТФ. 2014. Т. 40. Вып. 9. C. 86-94.

[9] Гуляев Ю.В., Абаньшин Н.П., Горфинкель Б.И., Морев С.П., Резчиков А.Ф., Синицын Н.И., Якунин А.Н. // Письма в ЖТФ. 2013. Т. 39. Вып. 11. С. 63-70.

[10] Тумарева Т.А., Соминский Г.Г., Светлов И.А., Морозов А.Н. // ЖТФ. 2008. Т. 78. Вып. 11. С. 119-122.

[11] Тумарева Т.А., Соминский Г.Г. // Известия вузов. Прикладная нелинейная динамика. 2009. Т. 17. Вып. 3. С. 17-54.

[12] Тумарева Т.А., Соминский Г.Г. // ЖТФ. 2013. Т. 83. Вып. 7. C. 121-124.

[13] Соминский Г.Г., Сезонов В.Е., Тарадаев Е.П., Тумарева Т.А., Задиранов Ю.М., Корнишин С.Ю., Степанова А.Н. // Известия вузов. Радиофизика. 2015. Т. 58. Вып. 7. C. $567-576$.

[14] Соминский Г.Г., Тарадаев Е.П., Тумарева Т.А. Острийный полевой эмиттер // Патент на полезную модель № 151235. Заявка № 2014117341/07 от 29.04.2014. Опубликовано 27.03.2015. 